\title{
Dancers in the Dark: Scientific Careers According to a Gender-Blind Model of Promotion
}

\author{
Ana M. GonzÁlez Ramos \\ Open University of Catalonia, Spain \\ Jose Navarrete Cortés \\ Secretary of Scientific Knowledge of Andalucia, Spain \\ Esther Cabrera Moreno \\ Knowledge Andalusian Agency, Spain
}

The disparity between men and women in science is a hot topic in gender studies and a relevant target of scientific policies. The leaky pipeline metaphor illustrates the decreasing number of women along senior positions in academia; however many questions remain unanswered. What factors progressively diminish the number of women in scientific careers and why do they appear to be less successful than their male colleagues? In order to discover new insight, this work compares men's and women's career paths by taking into account academic and family milestones achieved throughout the life course. An innovative and interdisciplinary methodology (from bibliometrics, statistics, and sociology) has been constructed to examine men's and women's trajectories. Findings display gender differences in scientists' trajectories. The evolution of scientists' careers reveals linear careers for males, whilst women develop non-linear careers. Motherhood emerges as a problem for developing linear careers. And collegiate decisions of gatekeepers seem to systematically disfavour women scientists' careers.

KEYWORDS life course approach, linear and non-linear careers, professional and family milestones, professional achievements, collegiate decisions, career paths

\section{Introduction}

Women's arduous climb up the professional ladder in science is supported by statistics. Women are underrepresented in some knowledge fields (the most 
male-dominated areas) as well as in senior categories, which impedes them from reaching influential positions. There is a low percentage of women in the top of scientific careers: only 28.4 per cent of full professors in Humanities are women and even less - 7.9\% - are engineering professors (EC 2013). There is also a decrease in the number of women who progress along successive stages of the professional ladder. According to the She Figures report (EC 2013), women make up 59\% of the postgraduate population, but that number decreases to $46 \%$ in PhD positions, $44 \%$ in assistant professor positions, $37 \%$ associate professors, and only $20 \%$ of full professors are women.

This problem has been illustrated by the 'leaky pipeline model' which uses aggregate data from different cohorts of women in various stages of their careers. The number of women who achieve upper positions in academia is decreasing, a fact which reveals the leak of women researchers and a gap which widens between men and women in postdoctoral phases. However, this metaphor is insufficient for identifying the factors that affect the dropout or slow progression of women. Our work, which attempts to shed light on this topic, uses innovative methodology involving the evolution of men and women scientists' merits along their life course (Elder 1994, Xie and Shauman 2003, Ceci et al. 2014).

Initially, it seems women scientists face a difficult progression in scientific profession because they encounter family and professional milestones throughout their life course at the same time. In other words, personal and professional spheres mutually interact and affect each other, rendering it difficult to make decisions in one sphere without it affecting the other (Evetts 2000, González and Vergés 2013). But there is another factor at play: the scientific career has been designed on the basis of a neutral progression model which is focused on traditional patterns of promotion for males and ignores circumstances involving women scientists (Bagilhole and Goode 2001, Benschop and Broun 2003). Despite the fact that women suffer a double burden as professionals and caregivers, the same rules and merit criteria prevail for the assessment of men and women's careers, ignoring the fact that family and gender issues are related to scientific productivity and professional achievements.

Even if women are greatly affected by family issues, a large number of women scientists agree with meritocracy, perceiving affirmative action as a threat to their worth. Rephrasing Son Hing et al. (2002), Sealy $(2010,186)$ affirms that 'people who believe strongly in the principle of meritocracy reduce their opposition to affirmative action when faced with the obvious presence of workplace discrimination'. In the interest of discovering new evidence, this work aims to shed light on non-equal conditions surrounding the development of scientific careers, and to confirm the importance of affirmative action with regard to gender.

In the present work we consider family milestones and their influence on research productivity along men's and women's career paths (Mauleón and Bordons 2009, Borrego et al. 2010, Mauleón et al. 2014). This approach distinguishes between their endeavours and entails the collection of 
information about how family and academic milestones interfere in researchers' promotion. To better understand the dynamics of professional trajectories, we develop an innovative methodology using bibliometrics (which studies the impact of scientific publications), statistical information regarding professional achievements (such as academic degrees, positions, etc.) and sociological categories regarding family formation. This instrument, which incorporates family criteria into a quantitative analysis of research merits, provides a novel picture of both male and female scientific careers.

The paper is divided into five sections. The first and second section show the theoretical framework and review the empirical model of analysis; the third section depicts the objectives, the study design and data collection method; the fourth section displays and discusses findings; and, finally, the fifth section exposes the main results and conclusions.

\section{Neutrality in science makes women dance in the dark}

Although progression in scientific careers is regulated by norms and labour laws, statistical data reveals that women are in a weak position. On the one hand, gender equality policies enact equal labour conditions, while meritocracy, which is supposedly based on a neutral evaluation process, regulates the promotion of candidates. The effectiveness of some of these rules is proved by the fact that, historically, there has been a clear increase in the enrolment of women working in science. On the other hand, social conditions engage male and female scientists differently which leads to unequal opportunities for success (Rees 2011), while subjective criteria contaminate the objective process of competition in the recruitment and promotion of new candidates (Van den Brink and Benschop 2011). Excellence in science is based upon trust in the assessment process and the neutrality of the evaluators; however some deeply-rooted practices in academia keep gender inequalities alive in scientific organizations. Furthermore, not only is the work-life balance a great obstacle for women pursuing individual goals, but it also reinforces gender stereotypes that corner women in lower and less prestigious categories. On the advancement of women in scientific careers, the She Figures report concludes they face two obstacles: a 'maternal wall' and a 'glass ceiling' (EC 2013, 7). This means that individual, as well as institutional constraints impede the progression of women in science. Their slow advancement is attributed to the effect of motherhood and a lack of determination to pursue professional goals. However, there are also institutional barriers and cultural practices that prevent equal opportunities for men and women scientists.

Gender stereotypes primarily affect women due to a double burden and work-life balance (Xie and Shauman 1998, 2003; Fox 2005; Ceci et al. 2014). The authors bring up some important factors regarding children's age, partner support and care facilities which may affect the scientific productivity of female researchers (Shauman 1998, Fox 2005, Ceci et al. 2014). Motherhood and family care present a serious handicap when academic milestones are overlapped with family issues in the same timeline (González and 
Vergés 2013). As Hochschild and Machung (1990) have said, the second shift entails factual and symbolic consequences. Firstly, female careers are affected by their own decisions about childcare and maternity. Even their husbands' decisions about mobility and successful careers may affect women's trajectories by interrupting or delaying their advancement (Ackers 2004). Also, directors, evaluators and senior colleagues judge women as less competent, and they fear career dropouts, low productivity or a less ambitious attitude than their male counterparts. Therefore, personal and social forces appear to be driving scientific careers because of the influence of a male culture affecting women's decisions, as well as gatekeepers' decisions about female careers (Evetts 2000).

Because access to research positions used to be limited to men only, it is easy to understand why scientific careers depend on a strong culture defined under masculine rules (Benschop and Broun 2003). Progression in careers evolves a linear trajectory across different stages, which candidates reach when they have accumulated a set of relevant merits. Scientific careers amass merits and collective recognition, which entails high productivity and constant progression (Buzzanell and Goldzwig 1991, Bagilhole and Goode 2001, Lyon and Woodward 2004). Thus, candidates' advancement depends on non-interrupted careers and high productivity patterns developed in linear careers. Candidates who are not strongly goal-oriented or who display non-linear trajectories are dismissed by gatekeepers in science under the assumption that they cannot bring forth increasing and outstanding merits (Bagilhole and Goode 2001, Benschop and Broun 2003).

Qualifications and skills of candidates are not the only requirements to progress in science. Even the selection of relevant criteria is questionable, because some merits are valuable while others remain marginal (Krefting 2003). A successful career depends on productivity measured by a series of merits, such as the relevance of the research topic, networking, peer review support, and mentoring. These factors interfere in the decisionmaking process of the gatekeepers. Although their criteria for leading a neutral assessment appear to be objective, subjective and cultural factors veil collegiate decisions when evaluating merits (Zynovyeva and Bagues 2011). Rees (2011) claims that there is a gender construct in the independence of the evaluations and in the criteria establishing the relevance of merits. And Siskind and Kearns $(1997,519)$ state that women are subjected to a double standard imposed by an institutional culture which is completely unrelated to the real attributes of candidates. A study in Dutch academia shows that faculty members make subjective judgments while serving on committee boards that select the candidates, while assessing their applications through 'objective merits'. According to this study, women are judged as less competent or unsuccessful candidates because of gender stereotypes that decrease their chances for obtaining the position (Van den Brink and Benschop 2011). Similar results were found by Moss-Racusin et al. (2012) who conclude that science departments exhibit a bias against female students.

Prejudices against female talent seem to contribute to the self-fulfilling prophecy that justifies the lack of women in science. Low expectations 
about female scientific trajectories not only bolster the decision of women to progress slowly or abandon their careers, but they also affect the likelihood of gatekeepers encouraging women into scientific careers. Fels (2004) found that women's modesty causes them to drop their goals more often than their male counterparts. González (2014a) found that women scientists are negatively judged when they show ambitious goals. Women act in accordance with social expectations about female aspirations, which make them seem less ambitious than their male colleagues; however, women who are strongly goal-oriented are practically ostracised because of gender stereotypes. Socialization in maledominated environments in science favours low profiles of women because 'ambition' is a social construct associated with men. Hegemonic values impose a disfavourable position of women when they are judged by a collegiate group of people. Heilman and Chen (2005) validate that altruistic behaviour enhances men's achievements, but not women's, because it is thought to be a natural attribute in women while it is judged as an outstanding behaviour in men. They point out that a violation of this norm tends to penalize people who break gender stereotypes because these rules are assumed as universal. So, because women are expected to have low achievements, women scientists who show an ambitious attitude are censured by their organization.

Hitherto, scientific organizations are fundamentally male-dominated and women are scarcely present at the top of influential networks. Committee boards and evaluation committees are mainly formed by men who introduce invisible biases due to gender stereotypes (Benschop and Broun 2003). Lack of support and isolation is a crucial factor for women pursuing successful careers. For this reason, some authors are claiming for higher participation of women in scientific committees of prominent organizations (Kemelgor and Etzkowitz 2001). It is necessary for women to be at the core of decisionmaking processes in organizations in order to recruit more women and broaden their influence in science. But if women who hold influential positions accept the merit-based system without critically evaluating it (Long and Fox 1995, Sealy 2010), social changes in organizations are impeded. A critical mass of women may make a difference but it is not enough for promoting deep social changes. As women assume the hegemonic culture of scientific institutions, a gender-approach attitude is difficult because those women are embedded in traditional male culture (Schiebinger 1999). The socialization of the candidates across different stages of their careers and throughout evaluation processes involves the acceptance of a gender culture despite being hindered by serious biases.

Progression of scientists depends on collegiate decisions rather than individual merits. However, meritocracy is constructed under the assumption of objectivity and the understanding that only personal effort leads to a candidate's success (Krefting 2003, Rees 2011). Instead, a great uncertainty is allocated on the collective decisions that translate prejudices into objective and fair process of evaluation. Literature shows evidence of female gatekeepers who also ignore the influence of social context in female careers because they believe they are real proof of the validity of meritocracy (Marsh 
2008, Zynovyeva and Bagues 2014). However, the promotion of candidates relies on great qualifications, confidence, luck, support and coaching from senior professors. Advancement of women scientists requires the patronage of female senior researchers (Anderson 2005). Since transparency in evaluations reveals insufficient support for women (Rees 2011), mentoring is a valuable resource to support young candidates.

\section{Women's trajectories along their life course}

The leaky pipeline (Berryman 1983, Xie and Shauman 2003) shows that women progressively decrease along research careers, while the gap between male and female achievements in science widens. Data visualization shows the loss of women along standard categories in degree programs and throughout the professional ladder in science; however, it does not explain why women may go slower or eventually leave their careers (Svinth 2006), nor does it indicate if there are re-entries at different points in their careers (Langberg 2006). The leaky pipeline is a cross-sectional analysis that collects data from different cohorts of scientists in various stages of their academic careers. It uses aggregate data from a population of scientists in different phases of their careers at a specific point in time. One of the limitations of this model is that it does not include a longitudinal study to explain the evolution of the phenomenon over time and, thus, fails to include information about personal careers of the researchers. Although the model offers a snapshot of scientific careers, it also presents serious weaknesses in its failure to examine the evolution of the researchers' cohort along the timeline. For the purpose of this paper, we will analyse researchers' career paths by observing the influence of professional and personal milestones on the scientists' trajectories.

The aim of the present work is to propose an alternative model of analysis for assessing how institutional and family conditions mutually affect scientific trajectories of men and women (González and Vergés 2013). Although previous studies have shown valuable information, we are still in the dark about the evolution of individual paths regarding the interference of family issues over time. This analytical model attempts to provide valuable insight into persistent obstacles for women in scientific careers. Indeed, we must discover how social factors shape the progression of men and women scientists, which the leaky pipeline model omits in its analyses.

Therefore, the aim of this work is to explore an innovative methodology based on bibliometrics and sociological categories about how men and women develop differently in their career paths. Data of the model shows professional and personal milestones along the life course. On the one hand, the model includes merits recorded in the male and females' curricula over their life course. On the other hand, it incorporates information about marriage and parenthood under the assumption that research careers overlap family plans and vice versa. To this extent, we will analyse the influence of social factors on professional advancement, track the biographies of men and women researchers and contrast their patterns to determine the influential 
factors on their careers. The model provides a graphical representation of scientific productivity, merits and positions, and considers the effects of age, marriage and childbirth. In the analysis, we distinguish between individual milestones and collegiate achievements, and whether merits only depend on individual effort or, on the contrary, depend on collegiate decisions, such as hiring and promotion processes.

We obtain information on professional achievement directly from a database that contains information about researchers' professional merits, but family records are complex to identify. There is a lack of statistics and surveys about family milestones related to researchers containing this kind of information, such as age of family formation, childbirths, and divorce. The Spanish National Statistical Institute (INE) establishes ${ }^{1}$ that the average age for marriage is 27.70 for women and 29.77 for men; correspondingly, the age when they have their first child is 29.98 for women and 32.05 for men. However, this data appears very general and inaccurate to depict demographic patterns of highly-educated women who may make different decisions about family due to professional goals, stress of the labour market, and personal callings.

Regarding Spain, two works support this hypothesis. De la Rica and Iza (2005) report that the interval age of first marriage for highly-educated women (holding university degrees) is 30-32 and they have their first child at 32-34, which shows that educated women delay marriage and motherhood, particularly in comparison with general figures produced by INE for Spanish women. A recent study about decreasing birth rates in Spain conducted by Esping-Andersen and colleagues $(2013,55,75)$ establishes the age of maternity for highly-educated women (holding university degrees) at 32-34 years old (the mean age is 32.9 for women and 33.3 for men). Furthermore, in the same study Esping-Andersen $(2013,61-62,76)$ claims that women born in 1965 have an average of 1.5 children, while women born in 1975 have 1.4, which reflects a diminishing tendency in the number of children over time and the effect of historical patterns. According to this report, unemployment is the basis for falling birth rates, as well as the delayed age of motherhood for highly-educated Spanish women. The author concludes that part-time employment, a poor child-care system, and a lack of family friendly policies toward the work-life balance all contribute to the delay of maternity. Thus, historical changes are essential when we introduce a gender approach into the analysis because of transforming patterns of men and women's roles.

\section{Research design and data collection}

\section{Objectives and hypotheses}

This work aims to explore a fruitful model of analysis that graphically displays the evolution of men's and women's scientific careers along their life course, taking into account both professional and personal factors. Beyond the leaky pipeline, this approach compares the productivity and major achievements rates at different age of researchers. Furthermore, to shed light 
on the impact of family milestones on professional careers, the representation of career paths is complemented by theoretical data about the age of the scientists' marriage and first child birth. We use an interdisciplinary approach from statistics, bibliometrics, and sociology for the construction of a synthetic indicator that outlines male and female careers. This indicator supports gender comparison and operates the theoretical framework related to leaky pipeline and maternal wall and glass ceiling, interpreting all these factors with empirical evidence. The purpose of this methodology aims at exploring the following objectives:

1. To map scientific trajectories of men and women and compare their career patterns. Literature suggests women develop non-linear careers that impede regular and successful careers. The analysis provides statistical and graphical evidence about differences on male and female trajectories. We sustain the hypothesis that men display linear careers and women non-linear careers.

2. To compare the progression of men and women in academia through the observation of overcoming stages and scientific productivity. The construction of a synthetic indicator shows the achievement of men and women across the timeline. Our hypothesis is that men gain these merits in progression while women display a low and non-continued level of productivity.

3. To address gender bias in science, including the influence of professional commitments, institutional rules, cultural values, personal choices and family issues, which involves the examination of academic records and social factors related to family formation. We overlap this information with details about marriage and first child birth, validating the hypothesis of a maternal wall.

\section{Data collection}

A burgeoning number of works use curriculum vitae analysis for assessing career patterns (Dietz et al. 2000, Bozeman et al. 2001, Bozeman and Gaughan 2011). The present analysis is based on the official items registered on the curricula database. The SICA database (Andalusian System of Scientific Information [Sistema de lnformación Científica de Andalucía]) is an official and mandatory registry to plan R\&I (research and innovation) public policy in Andalusia. The research community in Andalusia involves around 6,000 scientists with full-time contracts, the third largest region of R\&I personnel in Spain (FTE ${ }^{2}$ 15,064), behind the regions of Madrid (FTE 31,966) and Catalonia (FTE 27,058).

SICA provides information on Andalusian researchers. The data is gathered in a self-reporting system which uses automatic validation from international databases (for example, in the case of publication records) and also registers information about grants, contracts and positions, as well as honours and awards. Information is updated periodically by both researchers and an automatic system of validation which includes relevant scientific merits from a large population of researchers throughout their life course. 
It contains valuable information with complete, reliable, and accurate data. Records in the database include the date when the scientists reach several professional milestones including: graduation, $\mathrm{PhD}$ dissertation, first job, first tenured position, their participation in projects, conference organization, authorship in books, chapters of books, articles, number of citations, conference participation, poster presentations, relevance of journals and publishers through a peer-reviewed system (Scope, ISI of Knowledge, etc.), supervision of thesis and master thesis, membership in committee boards, position in academic governance, and awards. Table 1 shows the main items comprising the synthetic indicator RSI (Research Synthetic Indicator), which is a relative index:

The previous examination of our research design foresees an historical and generational effect on scientists' achievements, particularly for women scientists, which may provide unclear results to our analysis. Spanish R\&I has been transformed over the last few decades by the rise in the number of universities and research centres which, in turn, has increased the number of scientists since the 90s. This leads to an increase in internationalization (mobility, international collaboration, and networking) and scientific productivity (EU projects, publication rates, relevance of the citations, and number of patent registrations). In addition, demographic and social changes have promoted new gender patterns in Spanish society. A high number of women enrol in universities and become professionals; a gradual decline of the breadwinner model has led to other family models and male collaboration at home. In addition, gender equality law favours labour conditions for women with regard to maternity leave and transparency of the selection process (EC 2012). These factors might affect male and female cohorts of scientists and their career patterns.

TABLE 1

COMPONENT FACTORS OF THE RSI. (ELABORATION OF THE AUTHORS)

\begin{tabular}{|c|c|c|c|}
\hline \multirow[t]{6}{*}{1 Component } & Journal Publications & Publication in peer- & Mean ISI cites/items \\
\hline & Mean SRJ Scimago & reviewed journals & International ISBN \\
\hline & Books & Citations & Attendance in conferences \\
\hline & Book Chapters & Book edition & Peer-reviewed talks \\
\hline & $\begin{array}{l}\text { Attendance in international } \\
\text { conferences }\end{array}$ & $\begin{array}{l}\text { International ISBN chapter } \\
\text { book }\end{array}$ & \\
\hline & Peer reviewed posters & Invited talks & \\
\hline \multirow[t]{6}{*}{2 Component } & Projects & Leadership of competitive & Non-competitive projects \\
\hline & Predoc grants & projects & \\
\hline & Postdoc grants & Total financing & \\
\hline & Mobility & & \\
\hline & Contracts & & \\
\hline & Positions & & \\
\hline 3 Component & Honours and awards & $\begin{array}{l}\text { Positive evaluations from } \\
\text { their institution }\end{array}$ & $\begin{array}{l}\text { Research accreditations } \\
\text { from external agencies }\end{array}$ \\
\hline
\end{tabular}




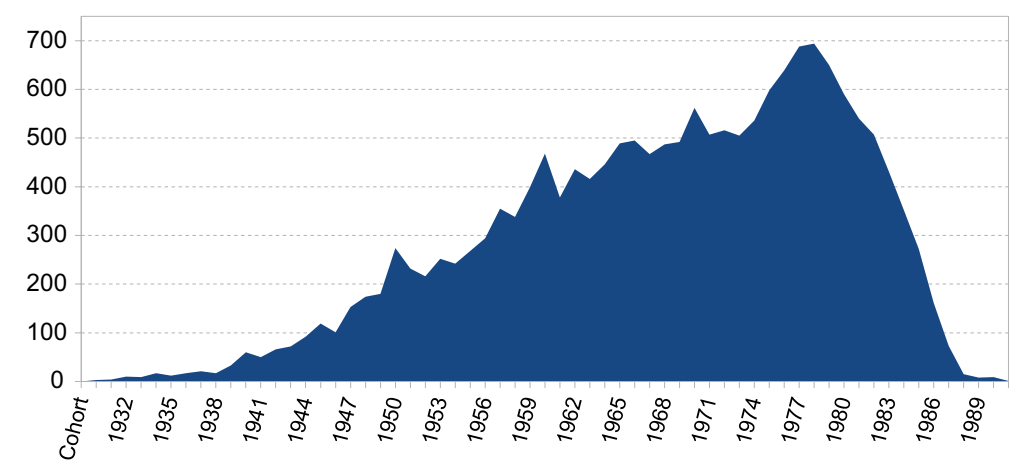

FIGURE 1 RSI Distribution all cohorts

In order to confirm this point, we check the distribution of the RSI across different cohorts of scientists in the SICA database (Figure 1) where we observe an increasing productivity pattern (above 500 points) for researchers born between the mid sixties and the early eighties, when rates begin to decrease due to outdated records. We compiled information from researcher cohorts who represented a more stable pattern in scientific productivity, from 1965 to 1987, excluding the youngest people in the database, as they were most likely students. In this way, we collect complete information about the cohorts of 23-45 year olds to include researchers from early to senior careers.

\section{SICA Database}

In the following table (Table 2) we can see that the distribution of men and women researchers by knowledge field is similar to EU figures (EC 2013). The data reflect the lack of women in traditional male research environments, showing particularly low rates in Engineering, Natural Science, and Agriculture (under 40\%) and a more equal distribution in Social Science and Health and Humanities. Common segregation patterns of men and women suggest that our findings should be generalized beyond the context population where we are analysing data.

Methodologically, we first collect individual records of scientists aged between 23 and 45 years old and compare the RSI of men and women researchers. The SICA database provides information on different merits in

TABLE 2

MEN AND WOMEN SCIENTISTS 23-45 YEARS OLD

\begin{tabular}{lrrr}
\hline & \multicolumn{1}{c}{ Men } & \multicolumn{1}{c}{ Women } & Total \\
\hline Agriculture & $71(60.7 \%)$ & $46(39.3 \%)$ & 117 \\
Health Sciences & $253(55.5 \%)$ & $203(45.5 \%)$ & 456 \\
Natural Sciences & $1023(65 \%)$ & $551(35 \%)$ & 1574 \\
Social Sciences & $1026(53.1 \%)$ & $908(46.9 \%)$ & 1934 \\
Humanities & $449(55.4 \%)$ & $361(44.6 \%)$ & 810 \\
Engineering & $751(77 \%)$ & $224(23 \%)$ & 975 \\
\hline
\end{tabular}


TABLE 3

SELECTED MILESTONES IN THE LIFE COURSE OF RESEARCHERS. (ELABORATION OF THE AUTHORS)

\begin{tabular}{ll}
\hline Academic milestones & Family milestones \\
\hline Date of graduation & Marriage \\
Date of post-graduates courses & First child birth \\
Mobilities & \\
PhD dissertation & \\
First job in academia & \\
Leadership of projects & \\
Permanent position & \\
Supervision of thesis & \\
Leadership of research group & \\
Responsibility in institutional governance & \\
Membership in committees and professional associations & \\
\hline
\end{tabular}

several phases of scientific careers. The layout of the RSI displays the male and female professional trajectory of scientists along their life course. These merits reflect relevant information about scientific progression. We dismiss merits which appear unsystematically or have an unclear influence on career progression. Instead, we select items with a clear connection to promotion (year of graduation, year of post-graduate courses, mobility experiences, etc.). The next table (Table 3) displays selected items (main academic and family milestones) used for the analysis. These merits happen sequentially along the scientific life course, but show different patterns for men and women scientists.

\section{Scientific careers of men and women scientists}

The RSI explores men's and women's careers focusing on career trajectories, and the extent to which female trajectories differ from an ideal model of progression. Through this analysis, it becomes clear that there are differences between men and women scientists developing their careers along the life course. Men and women achieve academic milestones at different points and in a different order on the timeline. Thus, women show dissimilar patterns to linear careers, which supposedly evolve as a sequential accumulation of merits. Differences between men and women appear when we examine the age range in which scientists achieve academic milestones.

The age range for men indicates that they achieve every milestone around the same population mean and, therefore, all of them exhibit similar patterns in developing scientific careers. However, the range for women presents wide limits that highlight women outlining more diverse patterns in their careers, and most likely shaping diversion routes to achieve professional goals. Previous studies support the idea that whilst men always appear as a homogeneous group with similar patterns oriented to professional goals and publication, women present diverse patterns and performance heterogeneity in research 
TABLE 4

MEAN AGE OF RESEARCHER ACHIEVING ACADEMIC MILESTONES. (ELABORATION OF THE AUTHORS)

\begin{tabular}{lcc}
\hline Milestones & Men & Women \\
\hline Graduation & 23.43 & $* 23.21$ \\
Post-graduates courses & 26.41 & $* 25.79$ \\
First-employment & 29.36 & $* 28.53$ \\
Mobilities & 29.45 & $* 28.84$ \\
PhD dissertation & 31.16 & $* 30.98$ \\
Membership committees & 31.96 & $* 31.25$ \\
Responsibility governance & $* 33.69$ & 34.14 \\
Permanent position & $* 33.89$ & 34.57 \\
IP projects & 36.53 & $* 36.12$ \\
Supervision of thesis & 36.97 & $* 36.88$ \\
Leadership of research group & $* 37.70$ & 39.73 \\
\hline
\end{tabular}

(Rier 2003). Some women show the same records as men whilst other women display patterns that represent a lagged progression and low rates of productivity. Rier (2003) concludes these women show low levels of self-confidence and are less disposed to risk-taking and competitiveness, whilst other authors claim that ambition and high self-confidence in women researchers depend on a social context that places them in the lower echelons (Fels 2004, González 2014a).

As a standard measure, the mean age indicates the age when scientists achieve the most relevant academic milestones. The following table (Table 4) displays the mean age of researchers in a group of milestones selected to represent progression in academia. According to this comparison, men and women show similar productivity rates overall, which justifies neither the gender gap nor the slow progression of women in scientific careers. Until they reach their thirties, the average age of men and women researchers correlates, which indicates there are many similarities between male and female scientific careers. In fact, women achieve certain academic milestones even younger than men, such as graduation, post-graduate degrees, first employment, mobility (rates are shown with asterisks in the column representing women). And after their thirties, women achieve their PhD dissertation, belong to board committees, lead their first research projects, and supervise their first doctoral thesis before men.

Only three of these selected indicators are accomplished by men earlier than women (highlighted with asterisks in the men's column); however, achieving these particular merits means recognition from gatekeepers and senior faculty members. These merits include holding a position in institutional governance, being hired for a permanent contract and leading a research team. Despite the precocity of women, who advance sooner in their careers in the majority of standard merits, men become a part of the scientific community and achieve institutional responsibility derived from peers' decisions earlier than women. 
It seems that women's achievements are based on individual milestones (i.e. obtaining degrees and their first employment contract), and even on agency decisions that prioritise their research careers (i.e. mobility and leading a research project). Conversely, men maintain slow progression rates at this stage of their careers, but advance more quickly than women when merit achievement relies on collegiate decisions by the support of senior colleagues. Although women are employed six years younger than their male colleagues, men hold a full position in academia approximately 1.5 years before women. Women lead their first projects at 36.12 years old whilst men reach this merit at 36.53; male scientists achieve peer recognition for a leadership position 2.44 years earlier than female research team leaders. Likewise, 1.5 years separate men (33.69) and women (34.14) when they hold an academic governance position which depends on appointment of senior scientists. In summary, female achievement appears feasible when hinged upon individual effort, but hardly achievable when is associated to collegiate decisions. This evidence suggests that women are weak in consolidation of their careers because of dependence of gatekeepers' recognition. The previous result sustains the prevalence of glass ceiling affecting women position in science, deeply rooted in subjective criteria of evaluators in the assessment of candidates' merits (Van den Brink and Benschop 2011) and mentoring men and women researchers (Anderson 2005, Rees 2011). Furthermore, this result validates the first hypothesis presented in this work.

\section{Linear and non-linear careers and a meritocratic model of progression}

A graphic representation of the RSI by sex exhibits some insights about men and women evolving through different trajectories during their life course. The next figure (Figure 2) displays both the men's and women's RSI which represents scientific productivity along the timeline. A first idea arises from this figure, which not only shows that the evolution of the RSI strongly depend on age, but also confirms the relevance of the life course approach in the assessment of individual careers in science. Therefore, an evaluation of the previous six years,

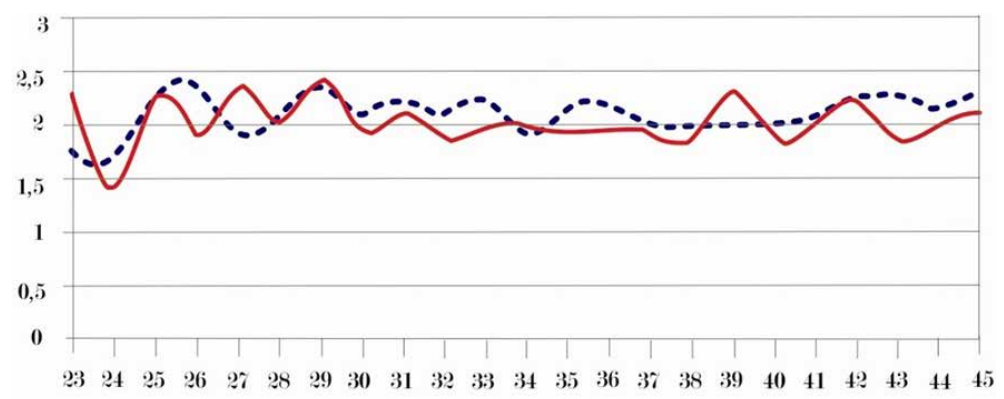

Men RSI Women RSI

FIGURE 2 Evolution of RSI in men and women's trajectories (Elaboration of the authors) 
which is the most common practice in scientific competition, is as arbitrary as it is uncertain based on the wavy tendency of scientists' trajectories.

Secondly, the figures exhibit that there is practically no gender gap until 30 years old when women appear to develop more slowly and at a more irregular pace than men. If in early phases they both show high productivity rates, the gender gap appears around the thirties negatively affecting women and persists throughout the rest of their trajectories. Male trajectories are similar to a linear career where candidates are continuously accumulating merits and advancing in successive phases of the career ladder. Globally, men present higher rates of productivity compared to women; where the male RSI is 1.7 at 23 years old and 2.3 at 45 years old, the female RSI increases from 2.1. to 2.3. In addition, the female RSI displays shifting gears during early phases (with positive outputs of productivity), during the late thirties (declining outputs), and some critical points in late careers. Thus, women's trajectories appear irregular and wavy, confirming that women more likely develop non-linear careers (Bagilhole and Goode 2001, Benschop and Broun 2003) and supporting the first hypothesis that leads this work.

A comparison of both male and female lines reveals the extent to which men's and women's trajectories are different. The male RSI is steadier than the female RSI in a global view but denotes significant dissimilarities over time. Women younger than 30 show higher productivity rates than men, who present steady records at this stage. The thirties seem to push women back in science, as shown by low productivity rates, when they begin to develop slower or more irregularly than men. Late stages are a fruitful period for men with a constant and high level of RSI but not for women who maintain irregular and limited productivity rates.

\section{The existence of a maternity wall}

The following section introduces family milestones into the analysis. So far data suggest the thirties are a key point in the advancement of women in science. Are marriage and partnership the cause of decreasing productivity rates? Is the birth of their first child the origin of non-linear trajectories for women? Does family formation equally affect men and women scientists or, on the contrary, is it potentially more negative for women than men? The next two figures illustrate the average age of men and women in RSI lines in order to discover some new evidence in response to these questions.

The next graph (Figure 3) illustrates the evolution of the male RSI based on the average age for marriage around 30-32 (De la Rica and Iza 2005) and the birth of their first child at 33.3 years old approximately, according to EspingAndersen (2013). For the male RSI, family formation seems not to influence productivity patterns, at this period placed above $2 \%$, and the birth of a first child seems to cause minor effect because the RSI level recovers quickly in the next years (34-35 years old). In fact, a brief, the steady phase of male productivity happens around 37-40 when any family circumstances hinder progression, but they hold a full profession at age 33.89. This smooth period 
of men researchers is short and thereafter the RSI grows reaching the highest rates as a likely consequence of achieving senior academic positions.

On the contrary, the distribution of the female RSI (Figure 4) shows a clear dependency on family formation (around 30-32 years old) and child birth (32.9 years old). A steady period of low productivity for women coincides with the most likely age for motherhood and care-taking responsibilities for young children, which confirms the hypothesis of a maternity wall as a particular handicap for women. According to the RSI, the age of children seems relevant to productivity rates for women researchers; when children are approximately 5 years old, women may recover their productivity level, although the RSI is irregular over time. A low period occurs at 32-38 years old and, contrary to the male RSI, the female RSI shows irregular and low productivity rates even in the senior stages.

However, despite this negative view about female productivity in mature stages, women still lead their first project and supervise their first doctoral student prior to men. This evidence indicates that the maternity wall does impede women's advancement and leads our research towards different factors preventing women from achieving high merits. Comparison of gender professional milestones at later phases in their careers indicates that men are

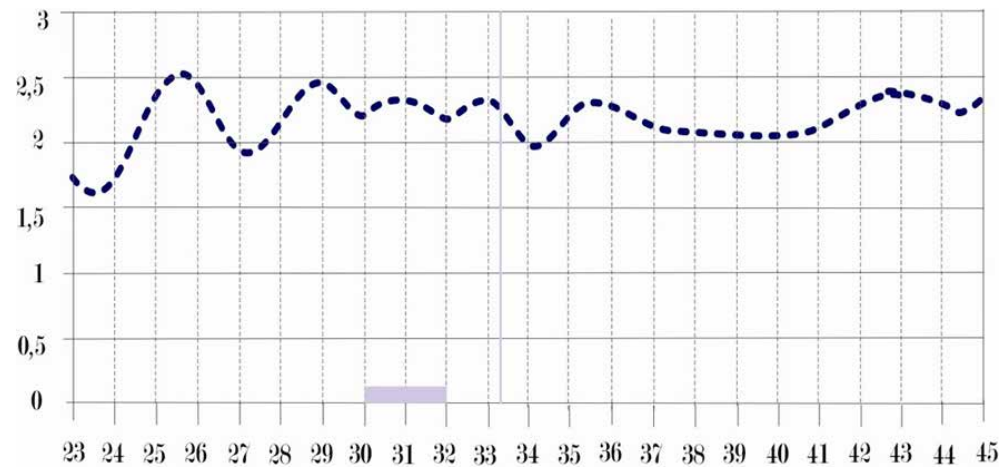

FIGURE 3 Evolution of the male RSI trajectory (Elaboration of the authors)

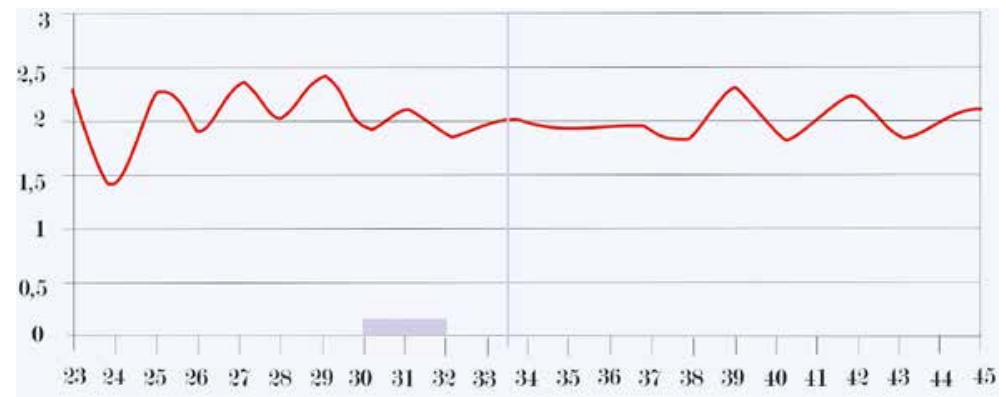

Women RSI

FIGURE 4 Evolution of the female RSI trajectory (Elaboration of the authors) 
more precocious in reaching certain kind of professional milestones related to collegiate decisions (i.e. permanent position, responsibility position in academic governance, and leadership of a research group). On the contrary, women achieve precocious merits more than men when their achievement depends on individual effort rather than on collegiate decisions, even after 33 years old. Similar to the way they receive their doctoral degree and reach first employment in the earlier phases, they also lead projects and their first doctoral student slightly younger than men. These merits depend on personal initiative rather than collegiate decisions taken by gatekeepers, pointing out institutional barriers as well as maternity issues preventing female advancement in science. In summary, although motherhood may be a paramount impediment for progression, nonfriendly environments and a male hegemonic culture in research institutions disheartens women from pursuing highly competitive careers. This evidence provides a fruitful explanation for dropouts, slow progression and less ambitious aspirations for women over 30 years old in science.

As our analytical model encompasses all women in the database population, we foresee some relevant findings related to heterogeneity of female career patterns. According to the previous results, it seems that a group of women exhibit similar or even higher rates of productivity than men, whilst other groups of women present low rates and slow progression. Similar to previous findings in this work, while males' careers show a similar trajectory and scientific productivity concentrated around the mean population, indicating homogenous profiles, women show a wide range of patterns derived from deviation around the mean in every professional milestone. Women scientists display more heterogeneous profiles according to diverse social factors: marital status (De la Rica and Iza 2005), motherhood, age of their children (Fox 2005), if they are married to other scientists (González 2014b), and social circumstances such as mentoring and the influence of non-friendly environments (Kemelgor and Etzkowitz 2001, Anderson 2005).

\section{In the dance hall}

Although women have been able to access academia for quite some time, their lagged position raises a serious question about the validity of the evaluation system in recruitment and promotion in science (Ceci et al. 2014). Assuming women are equally as competent as men, why are they at the bottom of the scientific ladder? Why are they concentrated in traditionally female knowledge fields? These issues reveal problems of efficiency in the organization of science (Schiebinger 1999). This work provides some evidence of the loss of excellence in science caused by the avoidance of gender issues. New insight in this work brings to light the importance of women in science and the silent problems they face. This section opens a discussion about the main results we found and proposes some feasible measures for eluding or minimizing negative aspects.

The appearance of fair play encourages women to enrol in the stimulating adventure of science, but the daily experience slowly diminishes their aspirations into more modest goals. Since women perceive neutral and objective 
criteria, they enthusiastically choose scientific careers; but under the light of the dance hall they face complex situations that make it difficult to pursue successful careers. Conclusive figures on the segregation of women point out that both individual and institutional barriers impede a more equal distribution of women in science. Under these circumstances, many women can only draw non-linear careers, far from the ideal career where the scientist moves along in a progressive, non-interrupted way and achieves recognition over time. Undoubtedly, scientific culture has to realize that different trajectories are possible in an excellent researcher; this simple idea should be reflected in the rules for assessment and should be understood by gatekeepers. As the result of this work shows, an evaluation of a period of time may be disadvantageous for women scientists who develop non-linear and wavy trajectories. This work provides helpful methodology to check and compare promising careers.

According to the present organization of science, the rules of play are assumed to be objective and are guaranteed to identify the excellence of candidates, which supposedly assures the recruitment and promotion of the best researchers. But candidates' competitiveness hinges on, for instance, the relevance of their research topic, belonging to an influential network, their fundraising capability and productivity rate, and the support (or lack thereof) of gatekeepers being part of committee boards in journals and funding institutions. Women also would benefit from the same rules if they had a clear comprehension of their male-dominated environment and adopted the right strategies. Thus, women are confident about the neutrality and fair play of the meritocratic system, while other aspects related to gender discrimination remain in the dark. They are also certain of employment laws and gender policies supporting female careers, but ignore invisible practices and biased rules that eventually dishearten them from pursuing ambitious goals. Gender stereotypes lessen women's opportunities since the work-life balance is clearly assumed as a burden to women and the 'self-fulfilling prophecy' acts on both sides, affecting the aspirations of women in scientific careers and promoting adverse opinions of colleagues and gatekeepers in recognising female talent. Likewise, factual consequences of the multiple roles that women take on as professionals, spouses, mothers, and scientists become a symbolic handicap for developing successful careers.

As some women show great determination, collecting accumulative merits over time just as men do, meritocracy is unquestioned. A common discourse puts women in the next top relevant generation of scientists without considering the still scarce number of women in the threshold, the extent to which they made a great effort and the fact that they are rare exceptions. A gendered culture shapes characteristics of candidates in science and their own aspirations based upon stereotypes. Most women frequently say: 'I don't want to sacrifice my children for uncertain goals' and gatekeepers respond: 'there are still not enough female candidates'. As Lorenz-Meyer (2014) states, absent gendering renders tensions and exclusions in a prevailing male-dominated culture, excluding other kinds of knowledge production. Therefore, messages about the real life-course for male and female researchers are necessary for us to be 
aware of their dissimilar challenges. Only when people consciously think about that may we understand why affirmative action is necessary because of its potential to correct unequal situations of competition between men and women embedded on singular circumstances. As we demonstrate in this work, there are multiple careers where women present more diverse trajectories. This analysis shows a paradoxical situation for women who easily reach goals depending on their own effort but who drop out in the middle of their careers because of a need to achieve the confidence of gatekeepers and peer recognition. Collegiate decisions are a bottleneck for promising careers of women scientists.

\section{Conclusions}

The empirical work discloses linear and non-linear trajectories for men and women scientists and uncovers the relevance of personal and professional milestones throughout scientists' life course. These two points highlight the existence of a gender bias in science based on male rules and a general acceptance of the idea that non-interrupted, accumulative, and linear careers are the only kind of careers that evidence excellence; but women present a great variety of career trajectories depending on their profiles and family characteristics. Most women show irregular, non-accumulative recognition and low productivity rates. Scientific policy is gender-blind regarding nonlinear careers and the impact of family and institutional barriers on women.

The relative indicator of productivity (RSI) supports the idea that women delay their progression due to family and institutional obstacles because they show higher achievements in early phases of their careers. A graphic representation of the RSI shows many similarities in men's and women's trajectories; this finding does not justify women's lagged position (see Figure 2). All women show high productivity in early careers, and more precocious results than men at this stage. On the contrary, men's achievements appear later at 37-40 years old and their RSI remains high along their life course (see Figure 2). Women scientists progress quickly when merit depends only on their own effort and agency, for instance, graduation rates (they graduate at 25.79 years old, whereas men graduate at 26.41), first employment (28.53 versus 29.36), mobility (28.84 versus 29.45$)$, doctorate (30.98 versus 31.16 ), leadership of projects (36.12 versus 36.53 ), and first thesis supervision (36.88 versus 36.97). However, women delay merits that rely on collegiate decisions which guarantee permanent position and being part of powerful faculty members, for example, holding governance responsibilities in scientific institutions (34.14 versus 33.69), full-time and permanent positions (34.57 versus 33.89), and leadership of a research group (39.73 versus 37.70). Thus, while women hold a permanent position 3.59 years after they receive their doctoral degree, men are full professors just 2.73 years after receiving the doctoral degree. Likewise, women lead a research group 5.16 years after they become full professors; men take 3.81 years to do the same. Predominance of an old boys' club explains this gender bias on women's trajectories. 
Social and family context interferes in scientists' trajectories, although this influence is clearer in women's careers than men's. Family formation does not seem to be an influential factor in male careers and child birth only affects them slightly, however both factors greatly affect women's careers. According to Spanish figures, a gender gap appears during the 30s which coincides with the first child birth for women researchers. Thus, a maternal wall is a clear obstacle for women, especially because motherhood coincides with challenging milestones in scientific careers when candidates have to reinforce networking and support from gatekeepers in scientific organizations. Data suggest that women never reach similar productivity rates as men scientists after that point in the timeline. Men receive recognition from their colleagues for previous professional experience and hold relevant positions in academia during a time that women depict irregular and low-productivity indicators. Therefore, we confirm that maternity issues and institutional barriers place women in a delayed position to reach high positions. This evidence of unequal conditions for men and women in scientific careers, in our opinion, may encourage more women to believe in the worthiness of affirmative action.

Methodologically, this work contributes to the advancement of analysing scientific careers and creating a novel assessment tool for scientific policy in professional careers. Visualization techniques based on trajectories of men and women scientists provide a powerful tool to analyse by gender and compare careers of candidates, distinguishing between candidates who have similar opportunities in their social environments (i.e. field of knowledge, family characteristics, and age). Beyond the 'leaky pipeline' metaphor, which presents some limitations, this methodology proposes to draw the representation of the RSI registered in the curricula of researchers and overlap it with personal and family events in the same timeline. In this way, our data reveal a clear influence on women's trajectories which raises the point that social context should be included in the intended objectivity and neutrality of professional progression in science.

One limitation of this work is the lack of face-to-face techniques for data collection. The lack of a supporting survey or interview makes it more difficult to determine if the family factor is stronger than career decisions or vice versa. Most likely, there is no single answer encompassing all women, but the identification of a group of women would create theoretical categorisation of social changes related to gender. This quantitative analysis can still provide relevant insight about the different profiles of women and patterns according to field of knowledge. Another interesting question about collegiate decisions emerges from the findings of this work. The impact of collegiate decisions on the advancement of women in research careers is lacking qualitative research that enquires both gatekeepers' and women's opinions. Gatekeepers should respond to the question of how their subjective opinions affect different styles of female work in academia in order to discover more about ambitious or non-linear careers during decision making. Women should address self-confidence, aspirations and how their goals 
are changing over time. Although some of these issues have been explored previously, some points still remain behind the curtain.

\section{Acknowledgement}

This research project was funded by the Spanish Ministry of Science and Innovation FEM2013-48225-C3-1-R. We would like to thank the suggestions of an anonymous referee.

\section{Notes}

1 Demographic indicators http://www.ine.es/daco/ daco42/sociales11/sociales.htm, 2011.

2 Full-time equivalent (FTE) researchers, where an FTE of 1.0 means that the person is equivalent to a full-time worker, while an FTE of 0.5 signals that the worker is only half-time. Data from 2010 are from http://www.idi.mineco.gob.es/stfls/ MICINN/Investigacion/FICHEROS/Estadisticas_ Indicadores/Indicadores_2012.pdf.

\section{References}

Ackers, Louise. 2004. Managing work and family life in peripatetic careers: the experiences of mobile women scientists in the European Union. Women's Studies International Forum 27:189-201.

Anderson, Daun R. 2005. The importance of mentoring programs to women's career advancement in biotechnology. Journal of Career Development 32: 60-73.

Bagilhole, Barbara, and Jane Goode. 2001. The contradiction of the myth of individual merit, and the reality of a patriarchal support system in academic careers: A feminist investigation. European Journal of Women's Studies 8: 161-80.

Benschop, Yvonne, and Margo Broun. 2003. Crumbling ivory towers: academic organizing and its gender effects. Gender, Work and Organization 10(2):194-212.

Berryman, Su E. 1983. Who will do science? Trends, and their Causes in Minority and Female Representation among Holders of Advanced Degrees in Science and Mathematics. New York: Rockefeller Foundation.

Borrego, Ángel, Maite Barrios, Anna Villarroya, and Candela Ollé. 2010. Scientific output and impact of postdoctoral scientists: a gender perspective. Scientometrics 83: 93-101.

Bozeman, Barry, James S. Dietz, and Monica Gaughan. 2001. Scientific and technical human capital: an alternative model for research evaluation. International Journal of Technology Management 22: 716-40.

Bozeman, Barry, and Monica Gaughan. 2011. How do men and women differ in research collaborations? An analysis of collaborative motives and strategies of academic researchers. Research Policy 40: 1393-402.

Buzzanell, Patrice M., and Steven R. Goldzwig. 1991. Linear and nonlinear career models: metaphors, paradigms, and ideologies. Management Communication Quarterly 4: 466-505.

Ceci, Stephen J., Donna K. Ginther, Shulamit Kahn, and Wendy W. Williams. 2014. Women in academic science: a changing landscape. Psychological Science in the Public Interest 15: 75-141.

De la Rica, Susana, and Amaia Iza. 2005. Career planning in Spain: do fixed-term contracts delay marriage and parenthood? Review of Economics of the Household 3: 49-73.

Dietz, James S., Ivan Chompalov, Barry Bozeman, Eliesh L. O'Neil, and Jongwon Park. 2000. Using the curriculum vita to study the career paths of scientists and engineers: an exploratory assessment. Scientometrics 49: 419-42.

EC [European Commission]. 2012. Enhancing excellence, gender equality and efficiency in research and innovation. Directorate-General for Research and Innovation. Brussels: European Commission.

EC [European Commission]. 2013. She figures. gender in research and innovation. statistcs on indicators. Brussels: European Commission.

Elder, Glen H. 1994. Time, human agency, and social change: perspective on the life course. Social Psychology Quarterly 57: 4-15. 
Esping-Andersen, Gosta, coord. 2013. El déficit de la natalidad en Europa. La singularidad del caso español. Colección Estudios Sociales n. 36. Barcelona: Obra Social La Caixa.

Evetts, Julia. 2000. Analysing change in women's careers: culture, structure and action dimensions. Gender, Work and Organisations 7: 57-67.

Fels, Anna. 2004. Do women lack ambition? Harvard Business Review April: 1-11.

Fox, Mary F. 2005. Gender, family characteristics, and publication productivity among scientists. Social Studies of Science 35: 131-50.

González, Ana M. and Núria Vergés. 2013. International mobility of women in science and technology careers: shaping plans for personal and professional purposes. Gender, Place and Culture 20: 613-29.

González, Ana M. 2014a. ¿Camuflaje o transformación? Estrategia profesional de las mujeres en carreras tecnológicas altamente masculinizadas. Educar 50: 187-205.

González, Ana M. 2014b. Inclusion of women in science. long-term strategies for alone or with partners' women. Géneros. Multidisciplinary Journal of Gender Studies 3: 459-82.

Heilman, Madeline E., and Julie J. Chen. 2005. Same behavior, different consequences: reactions to men's and women's altruistic citizenship behavior. Journal of Applied Psychology 90: 431-41.

Hochschild, Arlie, and Anne Machung. 1990. The second shift. New York: Avon Books.

Kemelgor, Carol, and Henry Etzkowitz. 2001. Overcoming isolation: women's dilemmas in american academic science. Minerva 39: 153-74.

Krefting, Linda A. 2003. Intertwined discourses of merit and gender: evidence from academic employment in the USA. Gender, Work and Organization 10: 260-78.

Langberg, Kamma. 2006. The gender gap in the public research sector. The case of Denmark. In Women in Scientific Careers. Unleashing the Potential, ed. OCDE, 61-76. Paris: OCDE.

Lyon, Dawn, and Alison E. Woodward. 2004. Gender and time at the top: cultural construction of time in high-level careers and homes. European Journal of Women's Studies 11: 205-221.

Long, J. Scott, and Mary F. Fox. 1995. Scientific careers: universalism and particularism. Annual Review of Sociology 21: 45-71.

Lorenz-Meyer, Dagmar. 2014. Reassembling gender: on the immanent politics of gendering apparatuses of bodily production in science. Women: a cultural review 25: 78-98.

Marsh, Herbert W., Upali W. Jayasinghe, Nigel W. Bond. 2008. Improving the peer-review process for grant applications. reliability, validity, bias, and generalizability. American Psychologist 63: 160-68.

Mauleón, Elba, and Maria Bordons. 2009. Male and female involvement in patenting activity in Spain. Scientometrics 83: 605-21.

Mauleón, Elba, Cinzia Daraio, and Maria Bordons. 2014. Exploring gender differences in patenting in Spain. Research Evaluation 23: 62-78. doi:10.1093/reseval/rvt030.

Moss-Racusin, Corinne A., John F. Dovidio, Victoria L. Brescoll, Mark J. Graham, and Jo Handelsman. 2012. Science faculty's subtle gender biases favor male students. Proceedings of the National Academy of Sciences 109: 16474-79.

Rees, Teresa. 2011. The gendered construction of scientific excellence. Interdisciplinary Science Reviews 36: 133-45.

Rier, David A. 2003. Gender, lifecourse and publication decisions in toxic-exposute epidemiology: 'now!' versus 'wait a minute!'. Social Studies of Science 33: 269-300.

Schiebinger, Londa. 1999. Has feminism changed science? Cambridge MA: Harvard University Press.

Sealy, Ruth. 2010. Changing perceptions of meritocraty in senior women's careers. Gender in Management: An International Journal 25: 184-97.

Shauman, Kimberlee A. 1998. Sex differences in research productivity: New evidence about an old puzzle. American Sociological Review 63: 847-70.

Siskind, Theresa, and Sharon Kearns. 1997. Gender bias in the evaluation of female faculty at the citadel: a qualitative analysis. Sex Roles 37: 495-525.

Son Hing, Leanne S., Bobocel D. Ramona, and Mark P. Zanna. 2002. Meritocracy and opposition to affirmative action: making concession in the face of discrimination. Journal of Personality $\mathcal{E}$ Social Psychology 83: 493-509. 
Svinth, Lisa. 2006. 'Leaky pipeline'- to be or not to be a useful metaphor in understanding why women to a disproportional degree exit from scientific careers. 6th European Gender Research Conference, $31^{\text {st }}$ August $-3^{\text {rd }}$ September, in Lodz, Poland.

Van den Brink, Marieke, and Yvonne Benschop. 2011. Gender practices in the construction of academic excellence: sheep with five legs. Organization 19: 507-24.

Xie, Yu, and Kimberlee A. Shauman. 1998. Sex differences in research productivity: new evidence about an old puzzle. American Sociological Review 63: 847-70.

Xie, Yu, and Kimberlee A. Shauman. 2003. Women in science: career processes and outcomes. Cambridge MA: Harvard University Press.

Zynovyeva, Natalia, and Manuel Bagues. 2011. Does gender matter for academic promotion? Evidence from a randomized natural experiment. IZA Discussion Paper No. 5537.

Zynovyeva, Natalia, and Manuel Bagues. 2014. The role of connections in academic promotions http:// dx.doi.org/10.2139/ssrn.2136888. (12/1/15).

\section{Notes on contributors}

Ana M. González Ramos is Senior Researcher at IN3 (Open University of Catalonia) and Coordinator of GENTIC research group. She is a sociologist and received her PhD in 2004. Her lines of research address gender studies and research careers paying attention to life course approach and cultural changes in scientific organizations.

Correspondence to: Ana M. González Ramos. E-mail: agonzalezram@uoc.edu.

Jose Navarrete Cortés, PhD is Director of Technical Office of Scientific Information System of Andalusia (SICA) in the General Secretary of Scientific Knowledge. During this time he has participated in the construction of National Standard for Curricula (CVN) articulated by the Ministry of Science.

Esther Cabrera Moreno is Technical Advisor at the Economy, Innovation and Science Department of Andalusia Government. She is an Authorized Statistical Agent of the Regional Statistics Institute. She has collaborated in the implementation of the Buenos Aires Manual of Scientifics' Trajectories promoted by the Iberoamerican Network on Science and Technology and (RICYT). 